\title{
FROM PROCRASTINATION TO REACTION! WHAT LEADERSHIP IS REQUIRED TO SHAPE THE FUTURE OF HEALTHCARE?
}

\author{
----The Chris Selby Smith Oration - July 2021 * \\ Dr DS Briggs AM \\ Editor in Chief of Asia Pacific Journal of Health Management
}

Correspondence:dsbriggs007@gmail.com

\section{PREAMBLE}

It is a privilege to be asked to present this Oration. Like many similar events, it pays tribute to a well-respected, revered, and past leader in our profession, in education, economics and life in general. Someone, who most of us would not have known personally nor about his involvement in the health system, particularly, SHAPE.

I have an abiding interest in health policy and health reform and how that has shaped our leadership and management of health services. Also, I have a view that healthcare should be viewed as a human service with differing groups of mostly health professionals providing care and services to individuals, groups, and communities. I see this in terms of engagement, wholistic and integrated and patient centred care. Some might say clients and suggest person centred care. Others in the quality and safety sector and the private health care industry, might suggest that people are consumers or even customers. For someone like me predominantly involved in the primary healthcare sector, we talk in addition to patients, in terms of communities, populations and of providers. Our language even goes to commissioning services rather than funding them.

Immediatelyjust by looking at the language we all use, we can see how it reflects our own bias based on our professional backgrounds and lived experiences. It also might suggest that healthcare is complex and continues to be 'siloed' and diverse in priorities and focus on how it might best be delivered. However, the issue of language and its meaning in healthcare is more than where we come from or where we work in the system.

Recently, I suggested that:

The intensity of the use of the term 'health reform' also seems to be in decline with the main language in the literature, being focused on safety and improved quality of care. This emphasis also has seemed to have reached a stable state suggesting to me that health reform should or might be shifting to an increased emphasis on health development. [2]

For inspiration, for this oration I went back to the 2017 Oration, presented by Professor Stephen Leeder [1] entitled 'The desirability of zero tolerance for procrastination'. An oration I enjoyed Immensely. That oration had some exquisite use of language. So, this preamble establishes my challenges and the parameters for the Oration.

The uniqueness of SHAPE, in my view is that it very effectively brought together health management academics and students, particularly doctoral students from across universities, together for the annual SHAPE Symposium, mostly in physical proximity together, but today through the medium of modern Zoom technology. This demonstrates an affinity between teacher and student that has added meaning to mentorship, role models and, a very distinct, caring and encouraging culture, enabling us to be collegiate. 
This had a significant impact on me personally, in that my doctoral research that I presented at an earlier SHAPE symposium became adopted by SHAPE and published as the 'SHAPE Declaration' [4], as an important policy perspective on health management and leadership. That discussion and the formulation of the SHAPE declaration occurred at the 2008 National SHAPE Symposium and was launched in the Asia Pacific Journal of Health Management [4] with an editorial by the then SHAPE President Godfrey Isouard and with an accompanying contribution from the then National President of the then ACHSE, Robert Grima.

The Declaration aimed to promote public debate on the reform of the organisation and management of health services. It arose from research that sought the perceptions and experience of senior health services managers from across Australia and New Zealand about the impact on their leadership and management roles during extensive health reform. This Declaration proposes a public debate about how health services might best be organized and effectively managed and proposes principles and parameters for reform. Well-qualified and experienced health managers are of central importance to the effective organisation and management of health services and to the success of future health reform. [4, p.11-12]

Subsequently in 2009 in Phitsanulok, Thailand at the 1st International Conference on Health Service Delivery Management, the 450 delegates, concluded the conference with a further Declaration, that comes after thirty years of the Alma Alta Declaration with a focus on the importance of capacity building, leadership, and health management. This declarationstates that:

Priority in resourcing and policy implementation should be given to developing leadership, management and governance as the means to strengthen health systems development.

Successful management of health services requires leadership and teamwork from managers who have positive personal and professional values and self-perceptions and, are empowered to engage with individuals and communities and to respond to the needs of the poor and to marginalised groups.

Leadership for health systems, public health and $\mathrm{PHC}$ requires that managers have access to high quality education, training and experiential health context and knowledge that equips them to operate effectivelyin health systems and;

A research culture is required that networks and engages in collaborative research to develop health management capacity and evidence as a basis for decisions, to guide policy development and that both challenges and aligns, researchers and operational health system professionals, citizens, and communities and importantly for us here today:

Outcomes identified from this conference for leadership and health management education training and research be conveyed to health organisations, professional bodies, local government, Ministry(s) of Health and Education and research funding bodies. [2]

These declarations are as relevant now, if not more so, while we live in the shadow of the Covid pandemic, sorely testing our public and political leadership and that of health systems.

Leeder in the 2018 Oration expressed frustration labelling the lost opportunities in healthcare as procrastination and plain bad management. In this 2021 Oration I take a similar perspective but see the 'devil' as an increase towards reactionary management, similarly wasteful and, dangerous when wrapped in the populism of State politics in a Federation, seems to have taken the leadership away from any unifying concept of a national health service. There is a lack of confidence and assuredness in our political and health system leadership. This context is raising serious concerns about trust and who de we turn to for advice and certainty of direction. We need to resist what I see as a tendency towards reactive leadership and management.

At the time of my research there had been continuous reform of health systems and two judicial or special commissions of Inquiry into health systems in Australia, in NSW and Queensland. Enormous and largely ineffective reform was a regular occurrence then. So, it is reasonable to state that the health manager role is complex, varied and contextualized because it is central to health reform and can be described as a unique role in implementing reform in professionally dominated organisations. 
To the extent that managers have formally developed management skills, they are mostly trained in and utilize rational and normative management theory and practice. Research suggests that the relationship between managers and professionals is a defining issue in health and introduces a particular kind of complexity, the powerful influence of professional subcultures and the constraining nature of that influence, is critical in the enactment of management roles.[5]

So, in earlier research, than mine it was suggested that health management needed to be seen in managing, professionally dominated complex adaptive health systems. This is said to involve relationship building, loose coupling, complicating, diversifying, sensemaking, learning, improvising, and thinking about the future. My subsequent research suggested that the central role of managers and leaders was sensemaking. I saw that in terms of communication and engagement, interpretation and understanding, flexible thinking, managing competing interests, critical thinking, big picture thinking, understanding, and managing self, resilience, and selfconfidence.[5]

It is often said that 'a paradoxical pattern of policy development' is described as 'reform without change and change without reform'. This author suggests that in highly centralised governance, health reform is difficult. $[2,6]$ Huber and colleagues suggest that the original $\mathrm{WHO}$ definition of health development in 1948, was based on a 'state of complete physical, mental and social wellbeing...' is no longer appropriate and in fact is counterproductive. Huber and colleagues go on to suggest that the existing definition 'minimises the role of the human capacity to cope autonomously with life's ever changing physical, emotional, and social challenges and to function with fulfilment and, a feeling of well being with a chronic disease or disability'. [2, 7]

These authors [7] go on to suggest that the diseases of the modern world are impacted by ageing and chronic disease. Even in developing countries where they may still address communicable diseases, they are also having to respond to ageing and chronic disease and that in all cases a complete absence of disease is unrealistic and unattainable. The current emphasis on Coronavirus (COVID-19) reinforces the fact that a complete absence of disease and not having to deal with communicable diseases are, both unrealistic and unattainable.
In my research and publications, I make much of engagement. I have previously stated [8 p,5-6] that "we the citizens and our communities substantially fund the health system' and 'that we have a collective responsibility for the moral stewardship of the resources'. According to Hofmeyer and colleagues [9 $\mathrm{p} .149]$ 'the bureaucratic domination of health systems have seen community engagement reduced to an 'advisory role'. The solution of course is for health organisations to have 'a broader focus on corporate citizenship' while moving to networks of cross sectorial deliverymechanisms, at the more local level.

There are compelling reasons for improved community and stakeholder engagement in healthcare it should be a compelling feature of democratic societies. The value of community engagement is evidenced in policies such as localism and in the principle of subsidiarity [8] and essentially suggest that services should be delivered and managed locally to meet local needs and decisionmaking should be made at the lowest level of government that can effectively be achieved. In addition, in health systems If communities are not engaged, then it is difficult to suggest that others have the capacity to solve those problems on their behalf.

Engagement implies receiving and giving advice, and demonstrating empathy, which is another important aspect of health language, that in this Covidage seems to have been corrupted and become reactive. Initially in Australia and most nation States advice on Covid was seen as authoritative, considered, and cautious. However, we are now recipients of conflicting advice from some of those sources that suggests political populism and a view from some health professionals that they not only know what is best for us but intend making that decision on our behalf, denying the autonomy of an individual's right to make their own decisions and to exercise their right to democratic freedoms!

In the wider primary healthcare context, we adopt the vision of an organisation as 'healthy people and communities.[10] This suggests that we need to value health above healthcare. [1 1,12] Health professionals and their organisations need to engage with people and communities in planning and decision-making about their health and how they might access the care required. This will require innovative across sector approaches [13] and this will require an understanding of the principles of localism, subsidiarity, and the concept of distributed networks of practice (DNOP) to engage and provide care. 
While writing this oration I also sit and listen to the daily missive of our State Premiers, flanked by a Minister for Health, a Chief Health Officer and warningly a senior police officer. The personalities differ from State to State. While accept that this is well intended, I need to suggest that data they use are raw figures without analysis or context that does not contribute to confidence and surety but increases community anxiety. Without that context it leads us to ill-informed or misinformed assumptions and decisions. In the post-covid period we now see a welcome departure, in some cases from this approach.

You can see missteps between lockdowns, while you see other nation States not locking down! Agrawal and colleagues [7] in a briefing paper, not at the time, peer reviewed but with international context, examine the impact of SIP, "sheltering in place', a US euphemism for our 'lockdown' approach, that suggests that there is little evidence of the efficacy of these measures and in fact, in some contexts suggest that they may also have negative consequences. There needs to be some serious sensemaking brought into the context of the public debate on measures that appear to be mostly implemented as a whim and, without any evidence that supports that the measure is best practice.

We are entering dangerous ground here with trusted advice, informed advice, media, and social media advice from all and sundry. If ever there is a need for health professionals to demonstrate trust and to act and engage ethically, it is now. If ever there was a threat to pursuit of national health service policies and to our need to respond actively to ageing populations, disability, mental health, and suicide, it is now. We will as in the past move beyond the pandemic, but can we reunify and work towards a more national perspective of health policy and healthcare?

In my view the biggest challenge we all face in the next decade will not be covid but how do we ensure that we can train and educate an adequate health workforce to respond to the need and funding promised by government from the recent Royal Commissions of aged care and disability. We are well placed to suggest to universities that now is not the time to pause and cut the education of health professionals, particularly in health management. Instead, they should be engaged with health systems to see how they can effectively engage in the workforce challenge!
A question here for you all. Are our universities aware that these Royal Commissions and the government response to them suggests there will be a need for an immense increase in the health workforce? Do you and your university feel confident that you can respond to that demand and increased demand? My sense is that universities are in a retraction phase, 'pausing' programs reducing staffing all because of a loss of international students? Am I correct?

Turning to leadership and management, in a recent editorial [14, p.2], I focused on some contemporary perspectives. I quoted, Elon Musk as saying:

top leaders spend too much time in front of spreadsheets and at meetings and not enough time thinking creatively and making things happen.

McKay [14, p.2] in that same editorial, emphasises that the 'strategic capacity of our leaders is the single - most important determinant of personal and organisational success.' Importantly, strategic leadership just happens to be 'all about context'. According to McKay [14, p.2] this means asking 'What are we not seeing? Being strategic requires five critical skills around being flexible, making good decisions, being a systems thinker, being focused and being an influencer.

In my research, that I asserted as the basis of the SHAPE Declaration is that healthcare managers and leaders need to:

Possess a deep contextual understanding of health systems, public policy, professional cultures, and politics. Have competency in organisational sensemaking as negotiators of meaning, active participants, constructors, organisers, and persuaders within health systems. [4, p, 11-12]

I further stated principles that in part included that public policy should focus on improving health outcomes, not be prescriptive but provide frameworks of responsibility and cooperation at the program delivery level and should focus on the needs of communities and populations. Structural arrangements and providers should be organised to meet the diversity of need and demonstrate good governance and management through proper engagement of structural interests. 
Amongst other aspects, health service structures should reflect the diversity of need and differences in geographic location of populations, culture, and healthcare needs and, have capacity to achieve intersectoral collaboration and, consider how adequate levels of accountability, trust and stewardship can be restored to the health system.

In a recently published article Olley [16 p.7] describes the theoretical construct of 'authentic leadership' as being about 'self-awareness, relational transparency, balanced processing and having an internalised moral perspective'. This author then describes the five principles of ethical leadership, which are respect, service, community, justice, and honesty. The author then confirms that the concepts of authentic leadership and ethical leadership are linked. He then invites us as leaders. to think about four aspects of leadership (virtues, values, vision, and voice) and align internal beliefs and values with the external behaviours to pursue the common good as they apply in a particular context. [16 p.7]

At this point I would like to ask you, the reader a series of questions. I want to challenge you to think critically and constructively about what I have suggested in this oration as being:

1. Is your organization active and supportive of health development and innovative public policy?

2. Is your organisation fit for purpose? Does the culture of your organisation adequately align with its purpose?

3. Are your staff predisposed to that purpose? In addition, is your management of staff holistic, humane, and integrated?

4. Is your organisation evidenced based and innovative, collaborative, multidisciplinary, providing stepped care or appropriate care?

5. Are we as researchers and academics educating and training health professionals that advances health professionals to engage in this future? [2]

Earlier researchers than I always used to ask the question 'Whose interests are being served?' and the other question was 'what problem are we attempting to solve?'. [8] You will note that in the references to authentic leadership by Olley [16] the quote focusses on authenticity and ethical leadership and suggests enacting this approach requires voice. The question is are we prepared to speak to demonstrate authentic and ethical leadership and see it develop in our public position, in our students and into the mainstream thinking of health leaders and managers? I am sure that there would be little debate where Chris Selby Smith might have stood in this discourse.

*This article is an edited version of the Oration which together with further detail about Chris Selby Smith can be accessed from the SHAPE website at http://shape.org.au/. I acknowledge feedback from my colleagues, Godfrey Isovard and Anne Smyth to the preparation of this oration.

\section{References}

1. Leeder,S. (2017). The Desirability of Zero Tolerance for Procrastination. Asia Pacific Journal of Health Management, 12(3), 8-10. https://doi.org/10.24083/apjhm.v12i3.49

2. Briggs DS. (2020) Health Development and Health Reform: Where to from here? Journal of Public Health and Development. Vol.18 No.1 January-April 2020

3. Chris SELBY SMITH July 1942 - September 2007 Tribute by Phillip McKenzie and Gerald Burke www.shape.org.au

4. Briggs DS. SHAPE Declaration on the Organisation and Management of Health Services: a call for informed public debate. Asia Pacific Journal of Health Management 2008; 3: 2

5. Briggs DS, Smythe A., Anderson, JA. (2012). In Search of Capable Health Managers: what is distinctive about health management and why does it matter? Asia Pacific Journal of Health Management 2012; 7:2

6. Hacker JS. Review Article:Dismantling the Health Care State? Political Institutions, Public Policies and the Comparative Politics of Health Reform. British Journal of Political Science. 2004; 34:693-

724,doi:10.1017/S0007123404000250

7. Huber M, Knottnerus JA, Green L, van der Horst H, Jadad AR. How should we define health? BMJ. 201 1;343:d4163,doi:10.1136/bmj.

8. Briggs DS. (2017) Progressing Health Reform Through Collaboration and Community Engagement. Asia Pacific Journal of Health Management 2017; 12:3

9. Hofmeyer A, Marck P. Building social capital in healthcare organisations: thinking ecologically for safer care. Nurs Outlook. 2008;56:1 45151.doi:10.1016/j.outlook. 2008.01.001

10. Briggs DS, Nankervis, R. Australian Primary Health Networks: Innovation in Improving Patient Care. National Conference on District Health Systems 
Management Development towards SDGs

Achievement. Phitsanulok Thailand, 2018.

11. Robert Wood Johnston Foundation. Building a culture of health. Accessed 2019 at

https://www.rwjf.org/en/howwe-work/building-aculture-ofhealth.html.

12. Briggs DS. Building a Culture of Health. Asia Pacific Journal of Health Management. 2017; 12:1, doi:10.24083/apjhm.v12i 1.85

13. Briggs, DS. Nankervis, R. Baillie, J. Turner, C. et al. Innovation to improve patient care in Australian Primary Health Network: an insider's perspective. Public Administration and Policy. 2019;22(2):1 11 -124, doi:10.1 108/PAP-09-2019-0017.

14. Briggs DS (2021). Leadership and management in the time of pandemics. Asia Pacific Journal of Health Management 2021; $16(2): i 915$. doi:10.24083/apjhm.v16i2.91

15. The Impact of the COVID-19 Pandemic and Policy Responses on Excess Mortality Virat Agrawal, Jonathan H. Cantor, Neeraj Sood, and Christopher M. Whaley NBER Working Paper No. 28930 June 2021 JEL No. $11,112,118,128$

16. Olley R. (2021) A Focused Literature Review of Power and Influence Leadership Theories. Asia Pacific Journal of Health Management 2021; 16 (2):i807. doi: 10.24083/apjhm.v16i2.807 